ISSN 2763-6860

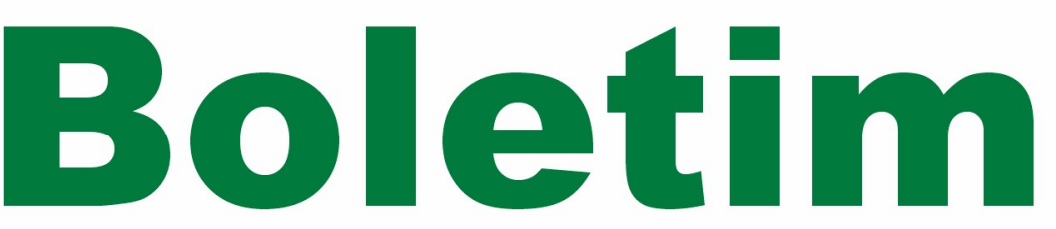

T É C N I C O S I F Número 06 - Volume 011 PROTOCOLO DE PRODUÇÃO DE MUDAS DE BAMBU POR ESTAQUIA EM DIFERENTES AMBIENTES DE ENRAIZAMENTO

Lindynez Milena Baquim et al. 


\section{PROTOCOLO DE PRODUÇÃO DE MUDAS DE BAMBU POR ESTAQUIA EM DIFERENTES AMBIENTES DE ENRAIZAMENTO}

Lindynez Milena Baquim ${ }^{2 *}$,Genaina Aparecida de Souza ${ }^{3}$, Osmarino Borges ${ }^{\dagger}$, Nathane Alves de Melo Imperatori $^{4}$, Rodrigo Nascimento de Paula ${ }^{5}$ e Gleison Augusto dos Santos ${ }^{6}$

\footnotetext{
${ }^{2}$ Universidade Federal de Viçosa, Graduanda em Engenharia Florestal, Viçosa, MG - Brasil. E-mail: < lindynez@gmail.com>.

${ }^{3}$ Universidade Federal de Viçosa, Programa de Pós-Graduação em Engenharia Florestal, Viçosa, MG - Brasil. E-mail: < genaina.souza@ ufv.br>.

${ }^{4}$ Universidade Federal de Viçosa, Graduando em Engenharia Florestal, Viçosa, MG - Brasil. E-mail: <nathane.imperatori@gmail.com>.

${ }^{5}$ Sociedade de Investigações Florestais, Viçosa, MG - Brasil. E-mail: <gerencia.tecnica@sif.org.br>.

${ }^{6}$ Universidade Federal de Viçosa, Departamento de Engenharia Florestal, Viçosa, MG - Brasil. E-mail: <gleison@ufv.br>.

*Corresponding author.

${ }^{+}$In memorium.
}

RESUMO - O bambu é uma gramínea pertencente à família Poaceae, da subfamília Bambusoideae com ampla distribuição geográfica. No Brasil é registrado uma das maiores diversidades desse grupo no mundo. É crescente o interesse de diversos nichos do mercado neste produto, como fibras, construção civil, móveis. Sendo assim, pesquisas que demonstrem de forma simples como esta cultura pode ser implementada através da produção de mudas é essencial para o setor florestal. O objetivo foi identificar melhores formas de propagação de duas espécies de bambu, Dendrocalamus asper e Bambusa vulgaris. As estacas foram obtidas a partir das gemas principais inseridas no colmo, sendo confeccionadas com três gemas cada. Após foram colocadas para enraizar em quatro diferentes tratamentos, pátio de rustificação sem sombreamento, pátio de rustificação com sombreamento de 50\%, casa de vegetação e casa de sombra. Cada tratamento composto por quatro repetições, dezesseis estacas por parcela. As mudas foram conduzidas em tubetes com substrato comercial. Após 90 dias foram feitas as avaliações nas estacas quanto a porcentagem de enraizamento, comprimento de brotações, quantidade de raízes e porcentagem de morte de estacas. Não observamos diferenças significativas quanto aos tratamentos, ou seja, os locais de condução das mudas. Porém, observamos diferenças quanto a espécie, a espécie B. vulgaris foi mais eficiente na produção de mudas. Pois, a porcentagem de enraizamento, o comprimento de brotações e a quantidade de raízes. Dessa forma, podemos concluir que essa espécie é de mais fácil propagação e melhorias no processo podem ser necessárias para espécies de maior dificuldade de enraizamento.

Palavras-Chave: Fibras alternativas, Enraizamento, Biomassa, Celulose. 


\section{1 . INTRODUÇÃO}

O bambu é uma gramínea pertencente à família Poaceae, da subfamília Bambusoideae com ampla distribuição geográfica, atingindo área total em todo o mundo superior a 30 milhões de ha (Du et al., 2018). Originário da Malásia, estima-se a existência de mais de 1300 espécies. Foi considerado um produto florestal secundário até seu recente surgimento como um importante recurso não madeireiro que pode substituir a madeira em muitas aplicações. Nas Américas, principalmente na sua região sul, são encontrados $40 \%$ das espécies de bambus lenhosos do mundo, aproximadamente 320 espécies em 22 gêneros. No Brasil é registrado uma das maiores diversidades desse grupo no mundo e a maior das Américas, com mais de 200 espécies descritas, entre nativas e exóticas, sendo mais de 170 endêmicas (Clark et al., 2015; Drumond e Wiedman, 2017; Felisberto et al., 2017). Uma das maiores reservas nativas de bambu do mundo $\left(180.000 \mathrm{~km}^{2}\right)$, está localizada no sudoeste da Amazônia, com $89 \%$ de todo o gênero de bambu e $65 \%$ de todas as espécies conhecidas na América, incluindo o Dendrocalamus asper, Bambusa tuldoides e Bambusa vulgaris (Pereira e Beraldo, 2016). A maioria das espécies de bambu é semélpara (um único evento de reprodução sexuada) e monocárpica (morrem após esse evento) tendo, portanto, um único evento de reprodução sexuada (Janzen, 1976; Silveira, 2001). No longo período que antecede o evento reprodutivo, os bambus se multiplicam vegetativamente por intermédio dos rizomas dando origem aos clones ou colmos que permanecem conectados formando uma moita (Saitoh et al., 2002).

Podem ser colhidos seletivamente anualmente, sem perturbar o sistema radicular e o solo o que os torna espécies eficazes para a conservação do solo e reduzindo a pressão sobre os recursos florestais existentes (Kaushal et al., 2020a, b; Tewari et al., 2016). A copa densa do bambu é útil para reduzir a erosão do solo reduzindo a energia cinética das gotas de chuva (Shinohara et al., 2010; Rao \& Jefery 2004: Rao et al., 2012). No Brasil, entretanto, a atividade econômica relacionada ao bambu ainda é restrita. Isso se deve principalmente à falta de conhecimentos científicos, agronômicos e tecnológicos especificamente desenvolvidos (Beraldo e Azzini, 2004; Drumond e Wiedman, 2017).
Contudo, o bambu é um forte candidato em substituição da madeira, por ser uma planta com crescimento rápido (em média $30 \mathrm{a} 35 \mathrm{~m}^{3} / \mathrm{ha} / \mathrm{ano}$ ), bom rendimento de matéria seca por hectare, capacidade de suportar até 100 cortes sem necessidade de plantio (realizado a cada dois anos), atuação como excelente sequestrador de carbono e baixa emissão de $\mathrm{CO}^{2}$ (Fang et al. 2018 ; Huang et al. 2018 ; Lu et al. 2018 ; Sugesty et al. 2015). Ainda podemos ressaltar que essa gramínea é rica em celulose, possui menor teor de lignina, bem como alto teor de holocelulose (Chin et al, 2020). Além disso, possui densidade básica superior ao eucalipto e pinus (Junior et al, 2019) e boas propriedades mecânicas (Perremans et al. 2018) e apresenta alto potencial para produção de celulose nanoestruturada para diversas aplicações industriais.

Levando em consideração as espécies que apresentam potencialidades para a composição de plantios comerciais (Souza, 2010), o Bambusa vulgaris e o Dendrocalamus asper apresentam considerável destaque pelo elevado valor econômico, adaptabilidade e rápido crescimento (Pereira \& Beraldo, 2008; Pereira \& Garbino, 2003; Mendes et al., 2010; Neto et al., 2010; Souza, 2010; Mognon et al., 2015; Brondani et al., 2017), porém, uma limitação importante para o desenvolvimento da cadeia produtiva do bambu refere-se ao seu deficiente processo de multiplicação.

A forma de propagação de bambu mais amplamente usada espécie é o método assexuado. O benefício primordial neste tipo de propagação é a obtenção de clones com uniformidade fenotípica, portanto manter características idênticas ao parental original; no caso de bambu, seções de colmos, ramos laterais ou rizomas são usados (Braga et al., 2017). Desde 2006, institutos de pesquisas e até mesmo as indústrias modernas com interesse no cultivo do bambu vêm investindo em tecnologias que melhorem a propagação dessas plantas com o intuito de elevar a qualidade genética e fitossanitária das mudas e reduzir os custos de produção, transporte e expansão da cultura, investindo na implantação de novas áreas de cultivo (Lemos et al., 2006; Guilherme et al., 2017).

Diante do exposto, o presente trabalho tem como objetivo identificar melhores formas de propagação de duas espécies de bambú, Dendrocalamus asper e Bambusa vulgaris.

\section{Boletim Técnico SIF 2021:06}




\section{MATERIAL E MÉTODOS}

Foram utilizadas duas espécies de bambu, a Dendrocalamus asper, coletada na Dendrologia, Departamento de Engenharia Florestal na UFV, e Bambusa vulgaris, coletada no Viveiro de Pesquisas do Departamento de Engenharia Florestal na UFV. As estacas foram obtidas a partir das gemas principais inseridas no colmo, sendo as mesmas confeccionadas com três gemas no total (Figura 1). Esses clones propagados, fazem parte do banco de germoplasma da Universidade Federal de Viçosa (Projeto BambuUFV).

Após a obtenção das estacas, essas foram colocadas para enraizar em quatro diferentes tratamentos (Tabela 1), cada tratamento composto de quatro repetições e dezesseis estacas por repetição, totalizando 256 estacas de cada espécie, em tubetes de $90 \mathrm{~cm}^{3}$, com substrato comercial Tropstrato Florestal a base de um mix de casca de pinus, fibra de coco, casca de arroz e vermiculita expandida, misturados com $2,16 \mathrm{Kg}$ de (Osmocote $(\mathbb{R})$ por metro cúbico de substrato na formulação 15-09-12 e 4,42 Kg de super fosfato simples por metro cúbico de substrato como adubação de base.

Após o preparo das estacas, essas foram acondicionadas em cada tratamento. $\mathrm{O}$ tratamento 1 foi instalado no pátio de rustificação a pleno sol durante os 90 dias. $O$ tratamento 2 também foi instalado no pátio de rustificação, porém com sombreamento de 50\%; o sombreamento foi retirado depois de 30 dias e o restante do tempo esteve a pleno sol. Já o tratamento 3 permaneceu em casa de vegetação com controle de temperatura, até $40^{\circ} \mathrm{C}$, e umidade, maior

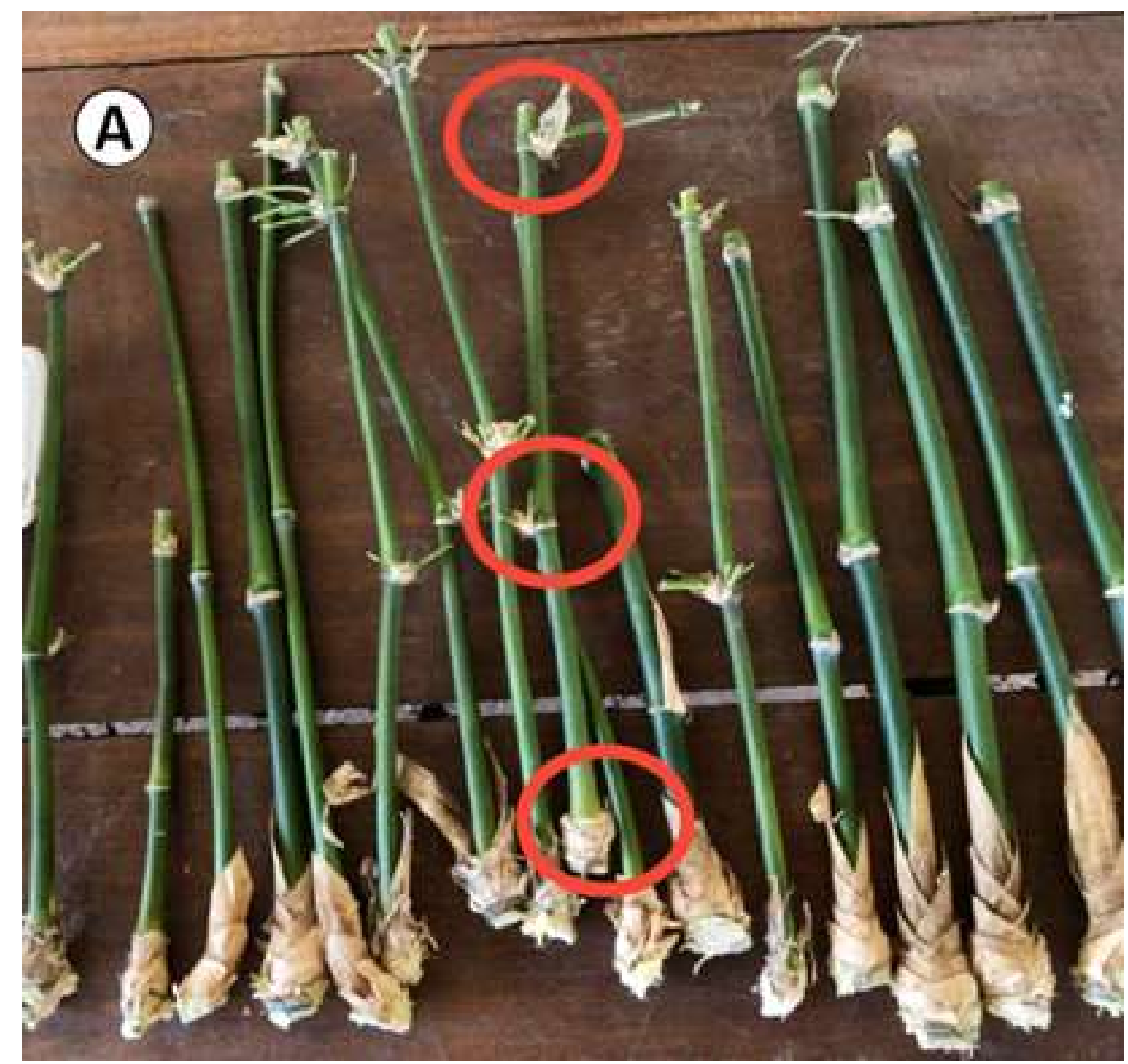

Figura 1 - Demonstração do padrão das estacas utilizadas com três gemas, evidenciadas pelos círculos vermelhos. 
Tabela 1 - Tratamentos para enraizamento de estacas de bambu das espécies D. asper e B. vulgaris.

\begin{tabular}{l|c}
\hline Tratamentos & Condição do ambiente de enraizamento \\
\hline T1 & Pátio de rustificação sem sombreamento \\
\hline T2 & Pátio de rustificação com sombreamento 50\% \\
\hline T3 & Casa de vegetação \\
\hline T4 & Casa de sombra \\
\hline
\end{tabular}

que $80 \%$, durante 30 dias. Em seguida, as estacas foram transferidas para casa de sombra por mais 30 dias e permaneceram 30 dias no pátio de rustificação. Por fim, o tratamento 4 foi colocado em casa de
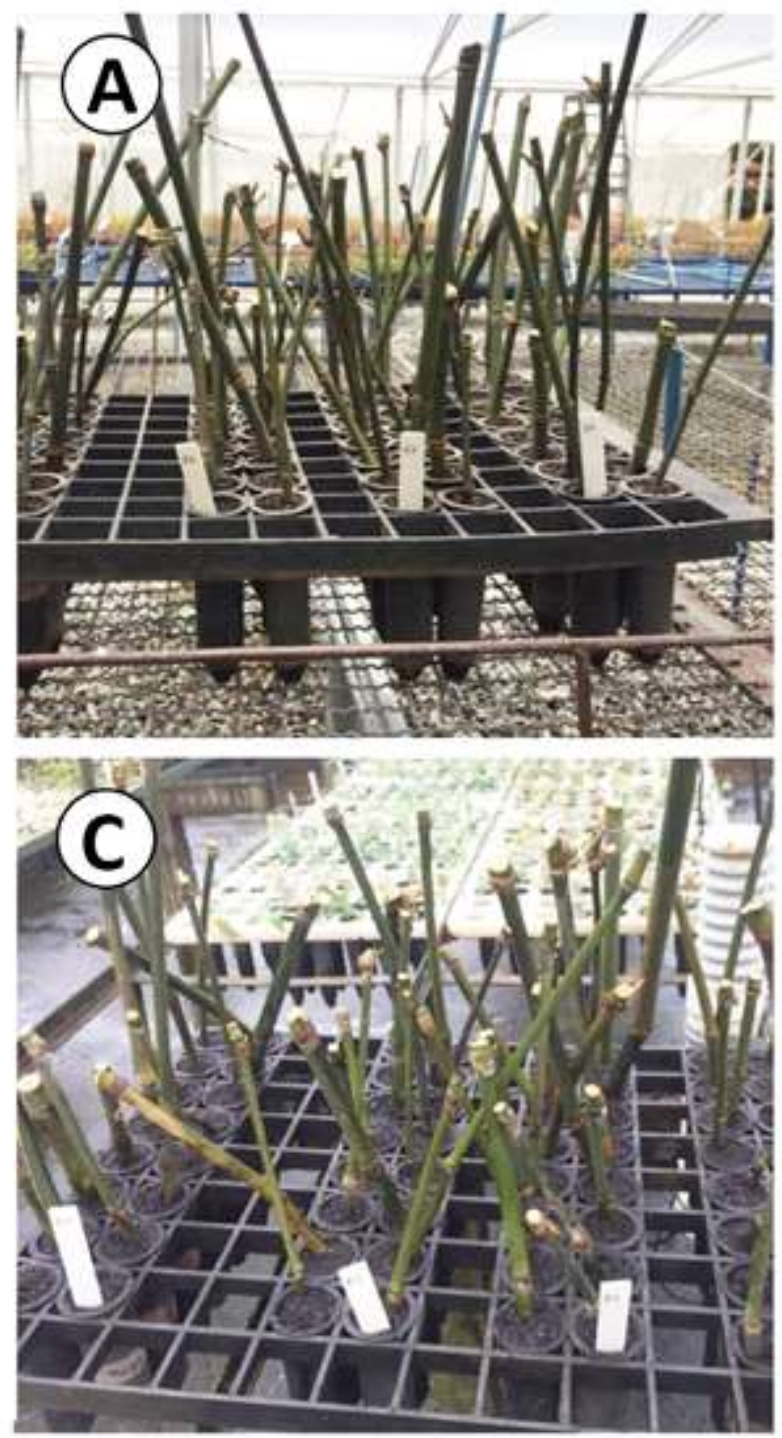

Figura 2 - Estacas de Bambu, distribuidas nos quatro tratamentos, (A), T1 - Pátio de rustificação, pleno sol; (B), T2 - Pátio de rustificação,

sombreamento $50 \%$; (C), T3 - Casa de vegetação e (D), T4 - Casa de sombra. sombra durante 30 dias e na sequência, as estacas que o compunham transferidas para o pátio a pleno sol durante os próximos 60 dias (Figura 2).

\section{3 . RESULTADOS}

Após 90 dias foram feitas as avaliações nas estacas quanto a porcentagem de enraizamento, comprimento de brotações, quantidade de raízes e porcentagem de morte de estacas. Não observamos diferença significativas nos parâmetros utilizados em relação aos ambientes de enraizamento que compunham os
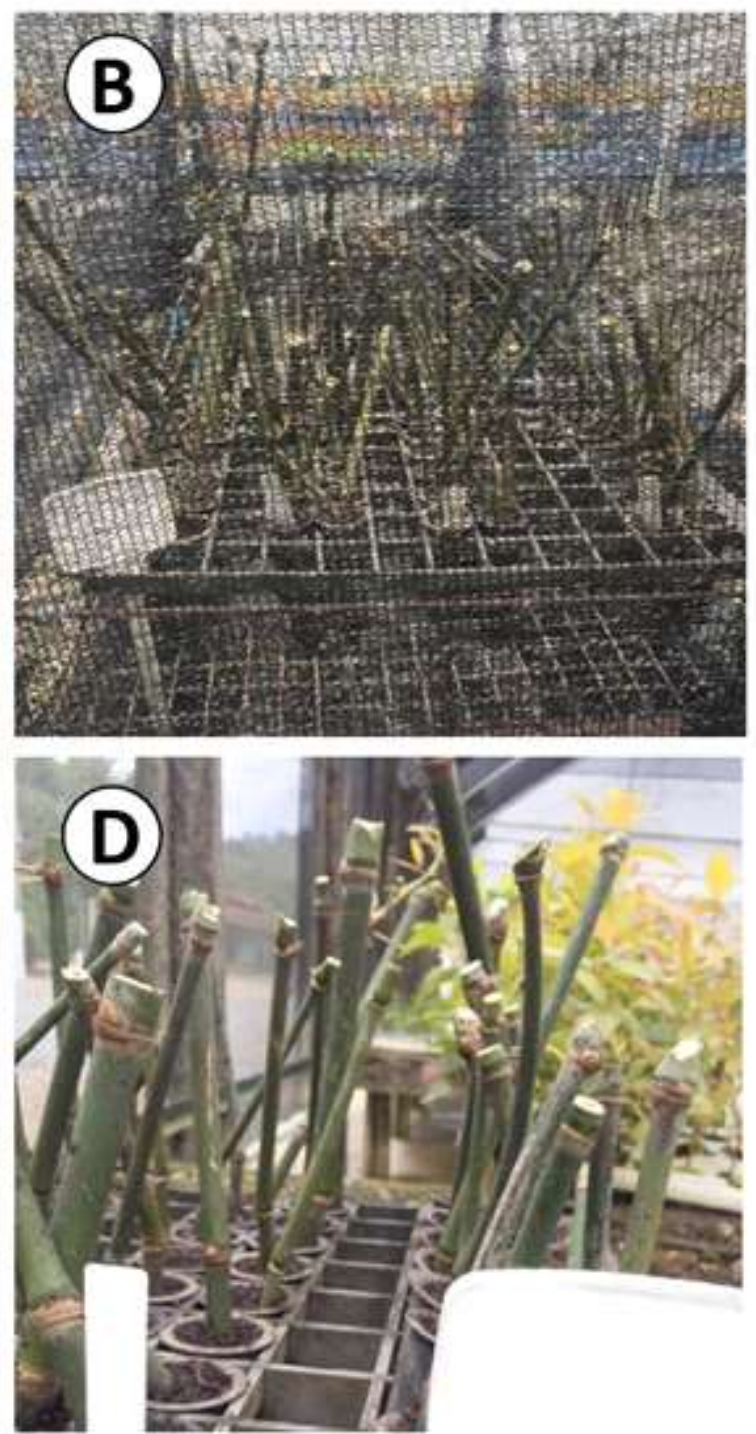


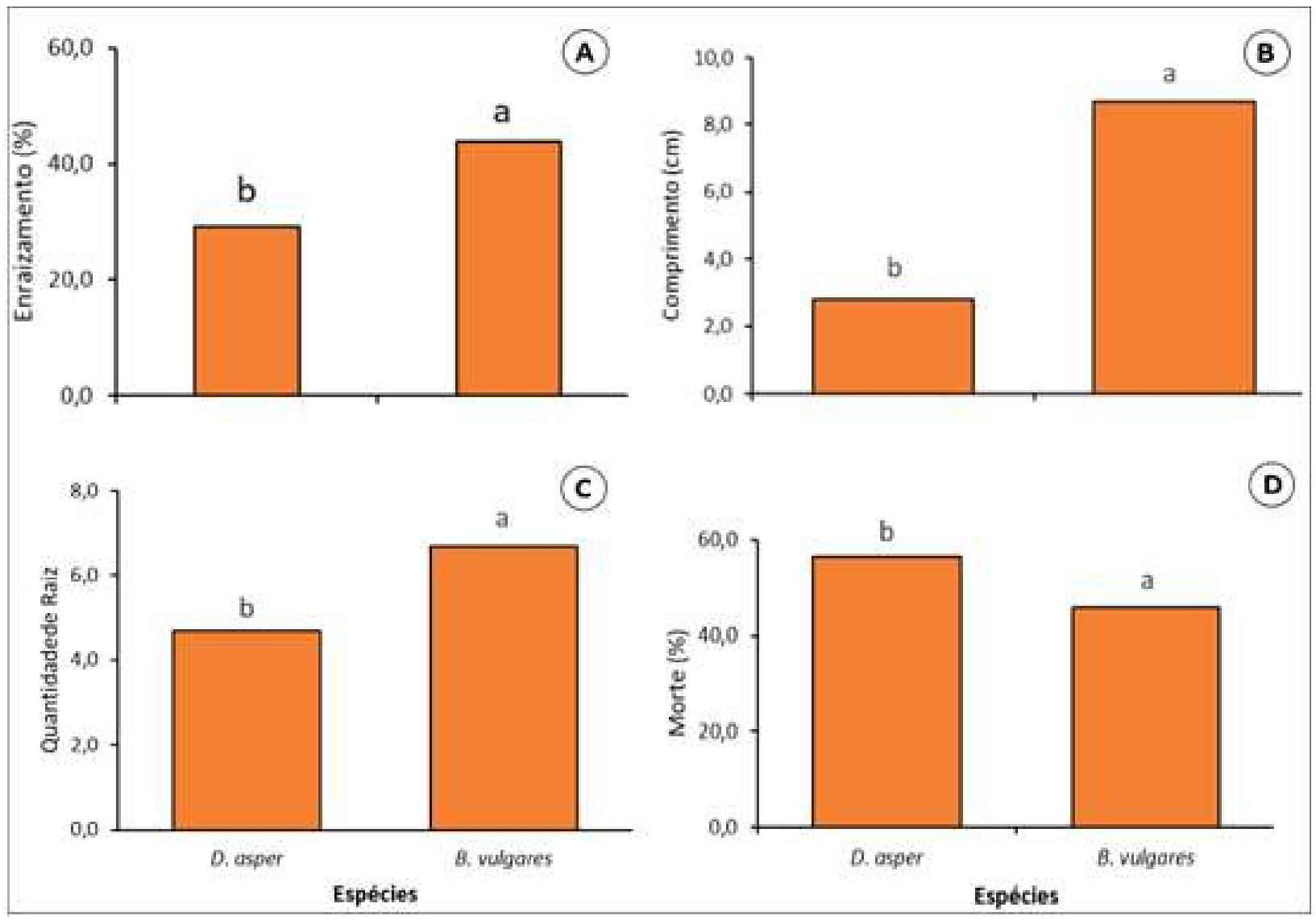

Figura 3 - Porcentagem de enraizamento (A), Comprimento de brotações (B), Quantidade de raízes C) e porcentagem de morte (D), de estacas de D. asper e B. vulgaris colocadas para enraizar em quatro diferentes ambientes.

tratamentos $(\mathrm{P} \leq 0,05)$. Ou seja, os ambientes Pátio de rustificação sem sombreamento; Pátio de rustificação com sombreamento 50\%; Casa de vegetação e Casa de sombra não apresentaram diferença significativa entre si $(\mathrm{P} \leq 0,05)$. No entanto, observamos diferença entre as espécies avaliadas, D. asper e B. vulgaris. Ficou evidente que a espécie $B$. vulgaris foi mais eficiente na produção de mudas. Pois, a porcentagem de enraizamento, o comprimento de brotações e a quantidade de raízes foram superiores para esta espécie (Figura 3 A, B e C). Similarmente, a porcentagem de morte das estacas fora significativamente inferior para B. vulgaris (Figura $3 \mathrm{D}$ ). Ressaltando a maior sobrevivência e vigor desta espécie em comparação a D. asper (Figura 3).

Através da remoção das estacas foram observadas a formação de raízes no substrato, o que demonstra que a utilização de estacas com três gemas é eficiente na formação de mudas (Figura 4). Apesar de visualmente haver diferença no padrão de enraizamento, como já mencionado, não houve diferença significativa entre os tratamentos testados $(\mathrm{P} \leq 0,05)$.

Foi possível verificar que as mudas produzidas através deste experimento apresentavam bom padrão de desenvolvimento para ambas as espécies na parte aérea ao final dos 90 dias (Figuras 5 e 6).

\section{DISCUSSÃO}

O método de propagação vegetativa para qualquer espécie vegetal varia em função de diversos fatores, tais como vigor da planta matriz, condições ambientais favoráveis, substrato adequado, idade fisiológica, dentre outros.

Não observamos diferença significativa entre os diferentes ambientes de propagação para 

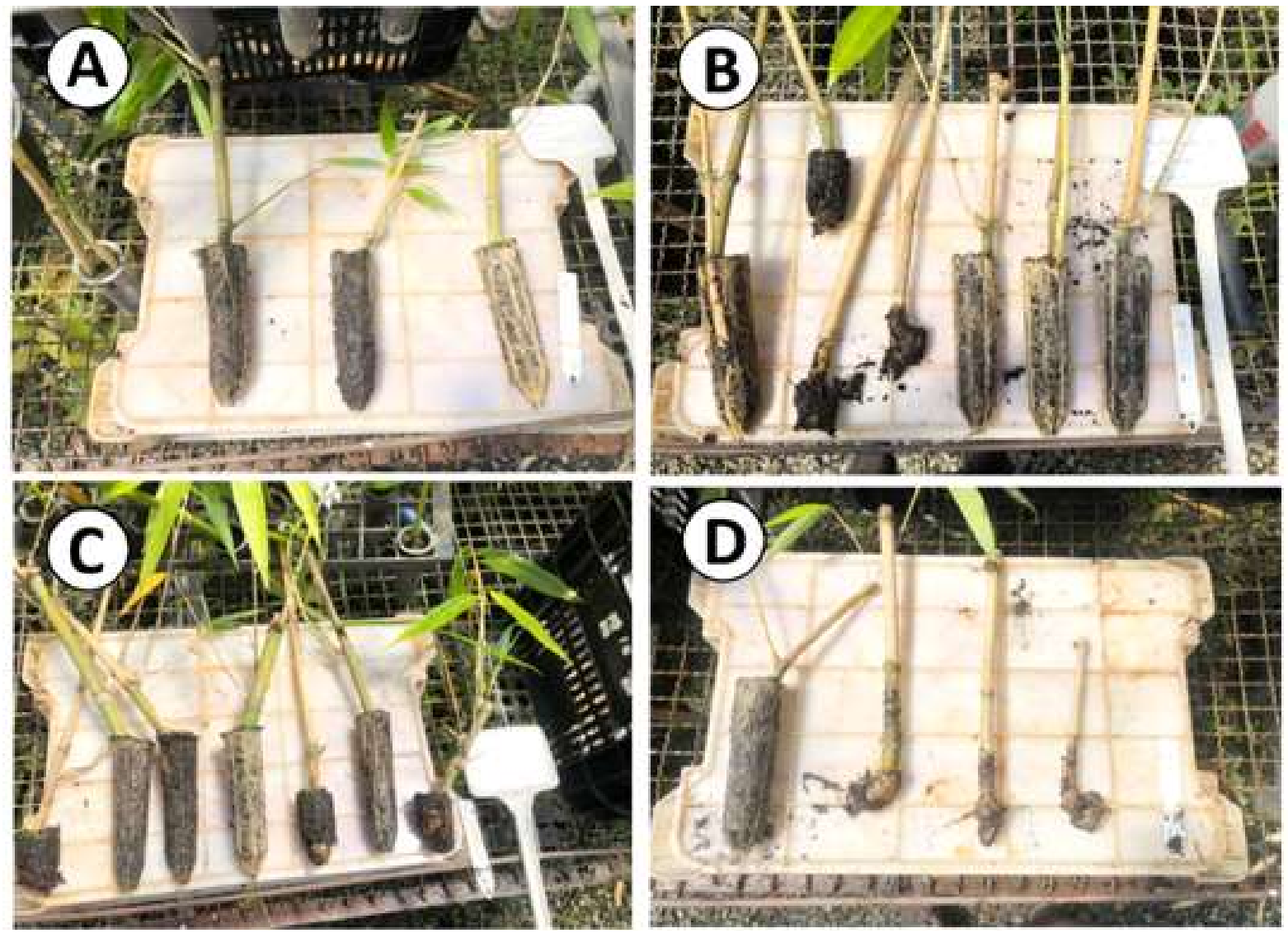

Figura 4 - Padrão de enraizamento de estacas de bambu nos diferentes tratamentos testados, (A), T1; (B), T2; (C), T3 e (D), T4.

as duas espécies testadas. Segundo Rasvi et al. (2015), trabalhando com estacas de Dendrocalamus giganteus, o gradiente de enraizamento está ligado a temperatura e umidade do local e do substrato utilizado. O que nos sugere que a variação ambiental (umidade, luz, temperatura), nesses locais, não foi o bastante para afetar as taxas de enraizamento, brotação e morte das estacas. Dessa forma, podemos concluir que todos os ambientes proporcionaram capacidade de enraizamento semelhantes. Resultado que está de acordo ao encontrado com diferentes métodos de preparação de propágulos de Bambusa vulgaris, B. tuldoides e Dendrocalamus giganteus, nos quais, não foram observadas nenhuma diferença significativa (Braga et al., 2017).

Diferentes espécies de bambu possuem diferentes caracteres fisiológicos e biológicos que determinam sua ecofisiologia e sua interação com o ambiente em que se encontra. B. vulgaris, é conhecido por apresentar dossel mais alto com rápido alongamento dos colmos (Kaushal, et al., 2021). O que pode explicar porque essa espécie apresentou maior comprimento de brotação em relação a $D$. asper (Figura 3B). Além disso, B. vulgaris, possui grande área do dossel devido à natureza arqueada de seus colmos. A comparação entre diferentes métodos de preparação de propágulos de espécies de Bambusa vulgaris, B. variabilis e $B$. tuldoides, demonstraram que a porcentagem de brotação de Bambusa vulgaris foi maior do que em Dendrocalamus giganteus (Niere et al., 2020).

Outro fator que pode ter afetado a diferença entre as espécies pode ser atribuído a diferenças nos níveis de hormônio endógeno (Sandhu et a., 2018). Como já descrito, o genótipo tem efeito significativo na frequência de indução de brotos, número de brotos / explante e comprimento de brotos em B. bambos e $D$. strictus (Kabade et al., 2009).

Vale ressaltar que o uso de estacas de galhos para propagação sem o uso de reguladores de crescimento, 

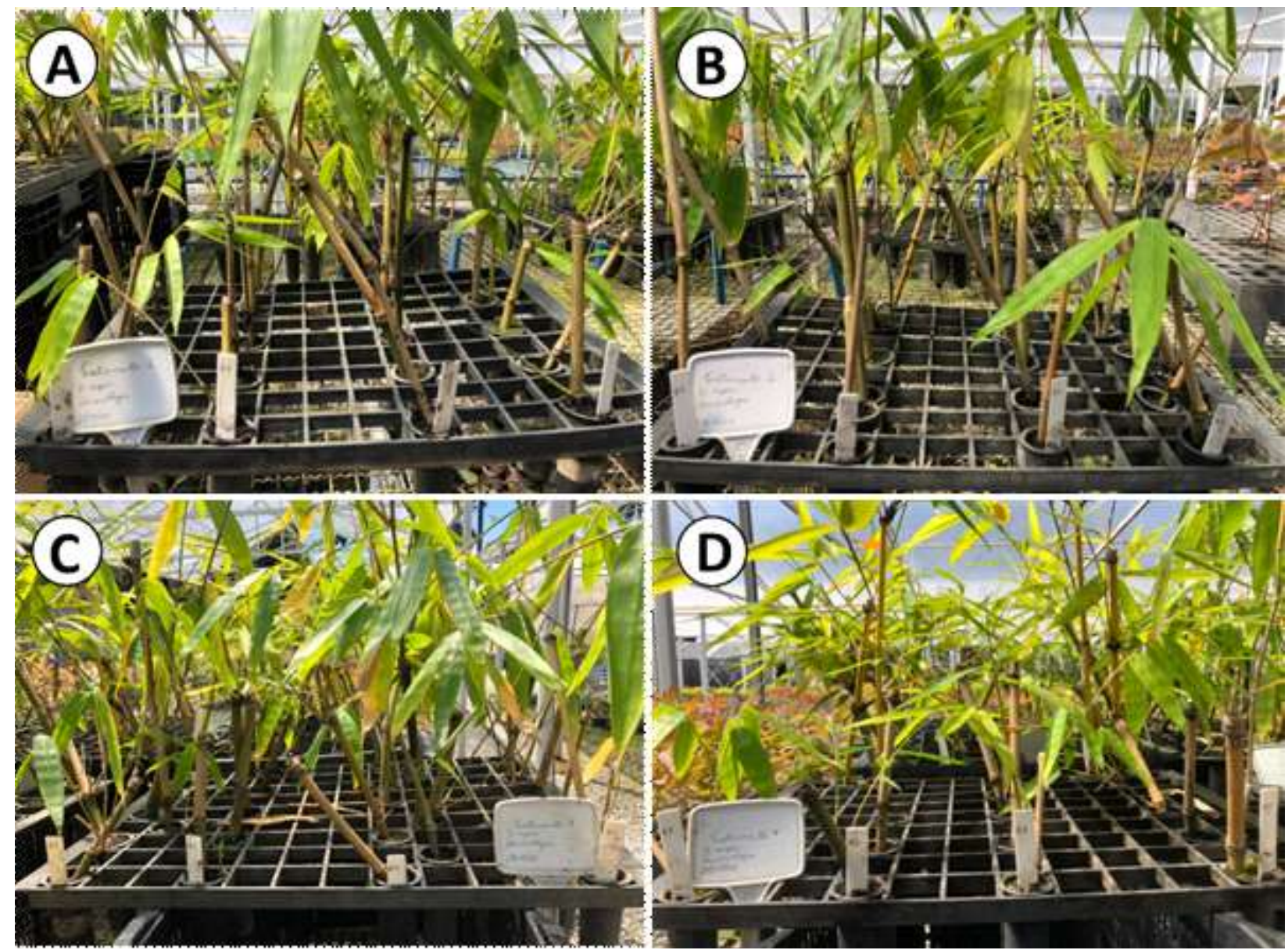

Figura 5 - Mudas de D. asper, produzidas de estacas com três gemas colocadas para enraizar após 90 dias.

foi mais eficiente para a espécie $B$. vulgaris, nas condições mencionadas. Semelhantemente ao observado no enraizamento em Bambusa vulgaris, em condições semelhantes (Nautiyal et al., 2007). Porém, outras técnicas como o uso de acético naftaleno ácido foram indicadas para $D$. giganteus. Ou seja, fica claro que as espécies respondem de forma diferente ao enraizamento. Ainda, que os tratamentos propostos neste estudo tenham proporcionado o enraizamento das duas espécies sem a aplicação de reguladores de crescimento, a presença destes reguladores poderia aumentar a porcentagem de pegamento. Uma vez que, a porcentagem de morte das estacas foi grande (Figura 3D), quando comparada com técnicas que utilizam os reguladores. O uso de acético naftaleno ácido, na concentração de $0,1 \mathrm{mg} \mathrm{L}-1$, aumentou o enraizamento, de estacas de Bambusa vulgaris, elevando o pegamento a $80 \%$ (Nautiyal et al., 2007).
De maneira semelhante podemos relatar que o maior comprimento das brotações das estacas em $B$. vulgaris se dê por suas características fisiológicas que permitem um alongamento mais rápido. Enquanto que a menor porcentagem de morte se associa a sua melhor capacidade de enraizamento. A maioria dos artigos evidencia a vantagem de usar vários brotos em vez de apenas um para a multiplicação de diferentes espécies de bambu; 2-3 rebentos em P. stocksii (Sanjaya e Rai 2005) e $B$. nutans (Negi e Saxena 2011a); três brotos em B. tulda (Saxena 1990) e B. bambos (Arya e Sharma 1998), 3-4 brotos em D. asper (Arya et al. 1999). Esse maior número pode proporcionar uma maior produção de mudas vivas ao fim do processo, diferentemente do observado aqui, onde utilizamos apenas uma estaca em cada tubete.

Em geral, verificamos que os métodos de preparo das estacas possibilitam o enraizamento das duas 


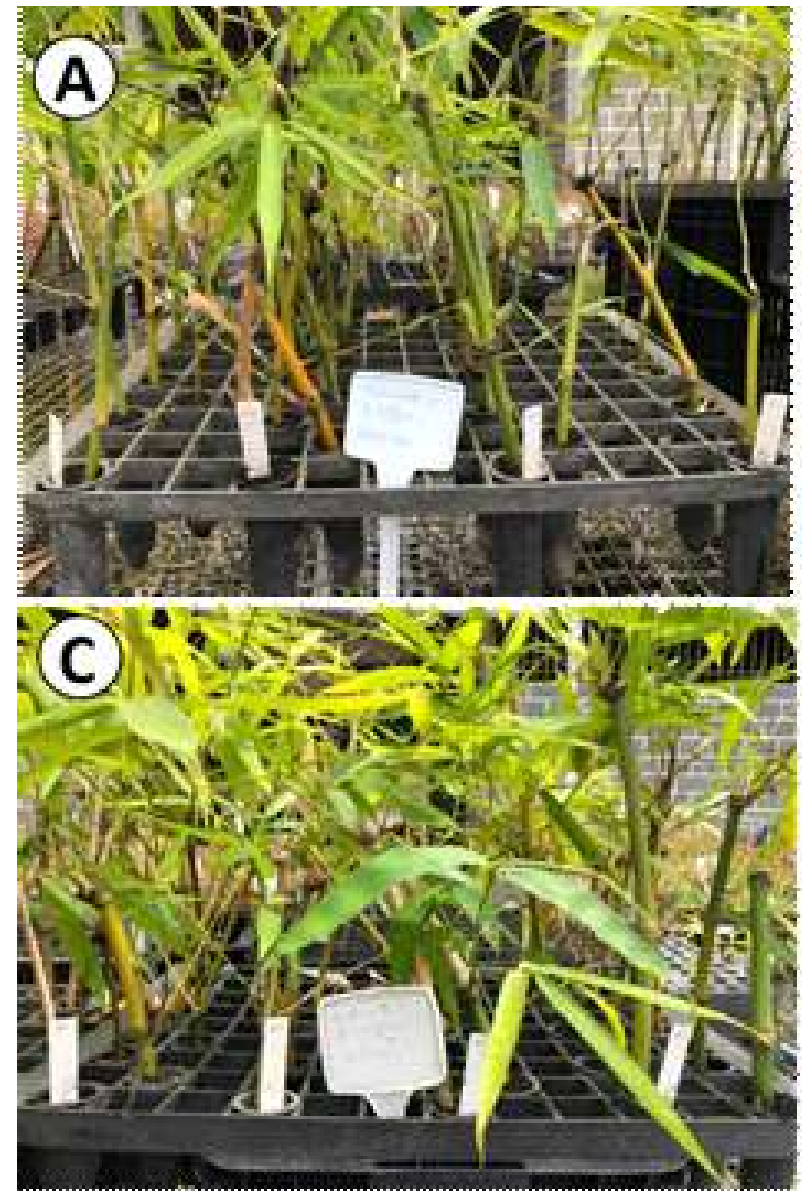

Figura 6 - Mudas de B. vulgaris, produzidas de estacas com três gemas colocadas para enraizar após 90 dias.

espécies independente do ambiente de enraizamento testados. O melhor ambiente para a produção de mudas foi o enraizamento em casa de vegetação.

\section{CONCLUSÕES}

Com o protocolo desenvolvido na Universidade Federal de Viçosa (UFV), a partir da sinergia de conhecimentos com o pesquisador Osmarino Borges, foi possível obter mudas de qualidade das espécies de bambu Dendrocalamus asper e Bambusa vulgaris.

A espécie B. vulgaris apresentou maiores índices de enraizamento em comparação com o $D$. asper, demonstrando maior adaptação aos protocolos testados.

Para as duas espécies o enraizamento em ambiente de casa de vegetação, demonstrou-se o mais adequado para a sobrevivência e desenvolvimento das mudas formadas.

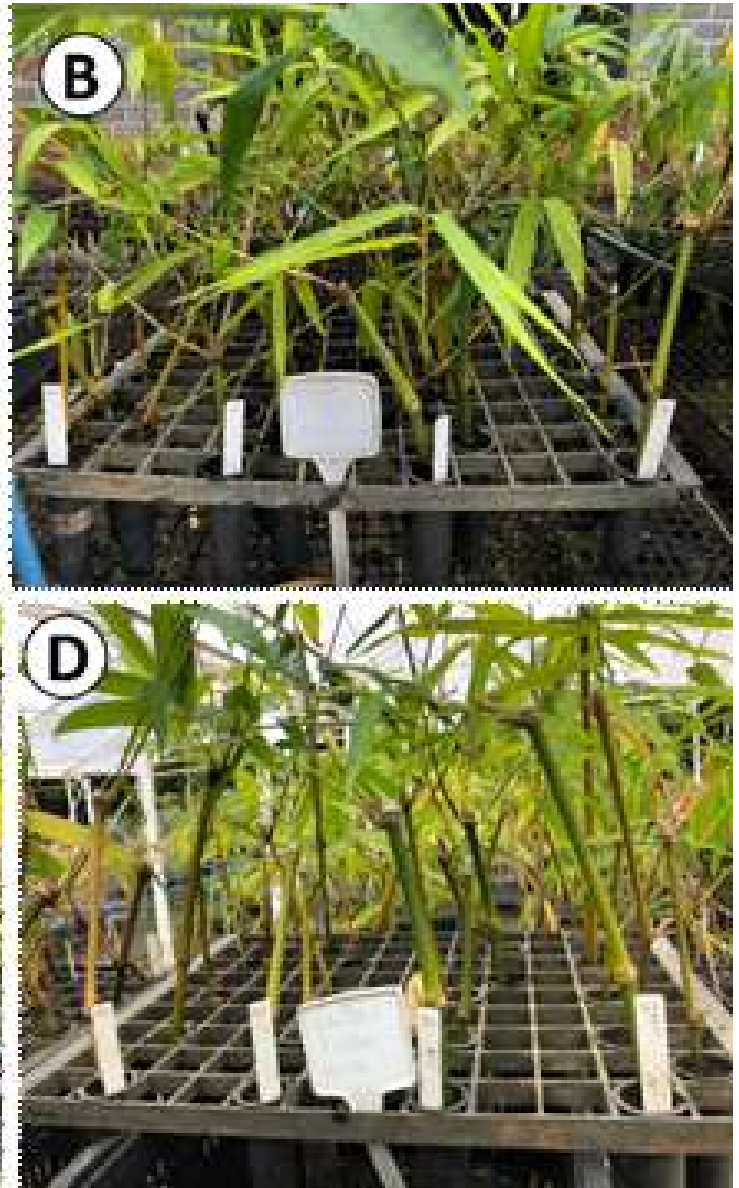

Com os resultados aqui obtidos é possível operacionalizar a produção de mudas em escala comercial dessas duas espécies, tornando a propagação vegetativa de espécies de bambu mais eficiente em relação a maioria das técnicas atualmente utilizadas para produção de mudas desse gênero.

Com base nesse conhecimento desenvolvido, novos passos podem ser dados na propagação de espécies de bambu, como por exemplo o teste da propagação por miniestaquia, a partir de minijardim clonal formado com as mudas produzidas a partir das técnicas utilizadas nesse trabalho.

\section{6 . AGRADECIMENTOS}

A Sociedade de Investigações Florestais (SIF) pelo suporte financeiro para realização desse trabalho e a Osmarino Borges (in memorian) um lutador incansável pelo desenvolvimento tecnológico da cultura do Bambu no Brasil. 


\section{REFERENCIAS}

Arya, S., Sharma, S. (1998). Micropropagation technology of Bambusa bambos through shoot proliferation. Indian Forester 124:725-731.

Arya, S., Sharma, S., Kaur, B., Arya ID. (1999). Micropropagation of Dendrocalamus asper by shoot proliferation using seeds. Plant Cell Rep 18:879-882.

Braga, R. M.; Santos, K. R.; Molina, R. A. R.; Nieri, E. M.; Melo, L. A. (2017). Propagação vegetativa de Bambusa vulgaris. Pesquisa Florestal Brasileira, v.37, n.90, p.229-234.

Chin, S. C., Tee, K. F., Tong, F. S., Ong, H. R., \& Gimbun, J. (2020). Thermal and mechanical properties of bamboo fiber reinforced composites. Materials Today Communications, 23, 100876.

Clark, L. G., Londoño, X., \& Ruiz-Sanchez, E. (2015). Bamboo taxonomy and habitat. In Bamboo (pp. 1-30). Springer, Cham.

Drumond, P. M., \& Wiedman, G. (2017). Bambus no Brasil: da biologia à tecnologia. Embrapa Acre-Livro técnico (INFOTECA-E).

Du, H., Mao, F., Li, X., Zhou, G., Xu, X., Han, N., ... \& Zhu, D. (2018). Mapping global bamboo forest distribution using multisource remote sensing data. IEEE Journal of Selected Topics in Applied Earth Observations and Remote Sensing, 11(5), 1458-1471.

Fang, C. H., Jiang, Z. H., Sun, Z. J., Liu, H. R., Zhang, X. B., Zhang, R., \& Fei, B. H. (2018). An overview on bamboo culm flattening. Construction and Building Materials, 171, 65-74.

Felisberto, M. H. F., Miyake, P. S. E., Beraldo, A. L., \& Clerici, M. T. P. S. (2017). Young bamboo culm: Potential food as source of fiber and starch. Food Research International, 101, 96-102.

Huang, C., Lin, W., Lai, C., Li, X., Jin, Y., \& Yong, Q. (2019). Coupling the post-extraction process to remove residual lignin and alter the recalcitrant structures for improving the enzymatic digestibility of acid-pretreated bamboo residues. Bioresource technology, 285, 121355.

Kabade, A.U. (2009). Studies on refinement of protocols for rapid and mass in vitro clonal propagation, evaluation of genetic fidelity and growth performance of bamboo species-Bambusa bambos (L.) Voss and Dendrocalamus strictus (Roxb.) Nees. Forest Research Institute Dehradun.

Kaushal, R., Tewari, S., Banik, R. L., Thapliyal, S. D., Singh, I., Reza, S., \& Durai, J. (2020a). Root distribution and soil properties under 12-year old sympodial bamboo plantation in Central Himalayan Tarai Region, India. Agroforestry Systems, 94, 917-932.

Kaushal, R., Kumar, A., Alam, N. M., Mandal, S. D., Tomar, J. M. S., Mehta, H., Lepcha, S. T. S., Long, T. T. (2021) Jayaraman Durai Assessment of eco hydrological parameters for important sympodial bamboo species in Himalayan foothills. Environ Monit Assess 193:468 https://doi.org/10.1007/ s10661-021-09231-7.

Janzen, D. H. (1976). Why bamboos wait so long to flower. Annual Review of Ecology and systematics, 7(1), 347-391.

Júnior, E. A. B., Lengowski, E. C., de Andrade, A. S., Venson, I., Klock, U., da Silva Júnior, F. G., ... \& de Muñiz, G. I. B. (2019). Bamboo kraft pulping. Advances in Forestry Science, 6(4), 791-796.

Lu, H., Zhang, L., Liu, C., He, Z., Zhou, X., \& Ni, Y. (2018). A novel method to prepare lignocellulose nanofibrils directly from bamboo chips. Cellulose, 25(12), 7043-7051.

Nautiyal, S., Negi, S. S., Biswas, S., Rathore, R. K. (2008). Farmers friendly cost effective propagation technique of bamboo. In: International conference on improvement of bamboo productivity and marketing for sustainable livelihood. Cane and Bamboo Technology Centre, New Delhi, pp 253-271.

Negi, D., Saxena, S. (2011a). In vitro propagation of Bambusa nutans Wall. ex Munro through axillary shoot proliferation. Plant Biotechnol Rep 5:35-43.

Nieri, E. M., Almeida, R. S., Melo, L. A., Cartolano, R. T. (2020). Methods of preparing propagules for tropical woody bamboo species. Sci. Agrar. Parana., Marechal Cândido Rondon, v. 19, n. 2, apr./jun., p. 196-199.

Pereira, M.A.R., Beraldo, A.L. (2016). Bambu de corpo e alma. (edn 2), Canal p. 352. 
Razvi, S.; Bakshi, M.; Nautiyal, S.; Hakeem, K. R. (2015). Seasonal variation on rooting response of branch cuttings of Dendrocalamus giganteus Wallich ex Munro. Journal of Bamboo and Rattan, v.14, n.1, p.11-25.

Rao, B. K., Kurothe, R. S., Pande, V. C., \& Kumar, G. (2012). Throughfall and stemfow measurement in bamboo (Dendrocalmus strictus) plantation. Indian Journal of Soil Conservation, 40, 60-64.

Rao, I. V. R., \& Jefery, B. (2004). SILVICULTURE Bamboos and their role in ecosystem rehabilitation. Encyclopedia of Forest Sciences. Oxford: Elsevier.

Saitoh, T., Seiwa, K., \& Nishiwaki, A. (2002). Importance of physiological integration of dwarf bamboo to persistence in forest understorey: a field experiment. Journal of Ecology, 90(1), 78-85.

Sandhu, M., Wani, S. H., Jiménez, V. M. (2018) In vitro propagation of bamboo species through axillary shoot proliferation: a review. Plant Cell Tiss Organ Cult 132:27-53 DOI 10.1007/s11240-017-1325-1.

Sanjaya Rathore, T.S., Rai, V.R. (2005).
Micropropagation of Pseudoxytenanthera stocksii Munro. In Vitro Cell Dev Biol Plant 41:333-337.

Saxena, S. (1990). In vitro propagation of the bamboo (Bambusa tulda Roxb.) through shoot proliferation. Plant Cell Rep 9:431-434.

Silveira, M. (2001). A floresta aberta com bambu no sudoeste da Amazônia: padrões e processos em múltiplas escalas.

Shinohara, Y., Onozawa, Y., Chiwa, M., Kume, T., Komatsu, H., \& Otsuki, K. (2010). Spatial variations in throughfall in a Moso bamboo forest: Sampling design for the estimates of stand-scale throughfall. Hydrological Process, 24, 253-259. https://doi. org/10.1002/hyp.7473.

Tewari, S., Banik, R. L., Kaushal, R., Bhardwaj, D. R., Chaturvedi, O. P. C., \& Gupta, A. K. (2016). Bamboo based agroforestry systems. In S. Kaushik, Y. S. Singh, D. Kumar, M. Thapliyal, \& S. Barthwal (Eds.), Bamboos in India (pp. 261-284). ENVIS Centre of Forestry. National Forest Library and Information Centre. FRI. 